Case Report

\title{
Dialysis and Pregnancy in End Stage Kidney Disease Associated with Lupus Nephritis
}

\author{
Goutham Sivasuthan, ${ }^{1}$ Rumbi Dahwa, ${ }^{2}$ \\ George T. John, ${ }^{2}$ and Dwarakanathan Ranganathan ${ }^{2}$ \\ ${ }^{1}$ School of Medicine, The University of Queensland, Brisbane, QLD 4027, Australia \\ ${ }^{2}$ Department of Nephrology, Royal Brisbane and Women's Hospital, Queensland Health, Butterfield Street, \\ Herston, QLD 4029, Australia
}

Correspondence should be addressed to Dwarakanathan Ranganathan; dwarakanathan_ranganathan@health.qld.gov.au

Received 9 August 2013; Accepted 24 September 2013

Academic Editor: W. Zidek

Copyright ( 2013 Goutham Sivasuthan et al. This is an open access article distributed under the Creative Commons Attribution License, which permits unrestricted use, distribution, and reproduction in any medium, provided the original work is properly cited.

Female patients with systemic lupus erythematosus are often of childbearing age at diagnosis, and though fertility in these patients is similar to the general population, successful pregnancy remains a rare occurrence. This incidence is, however, increasing and the management of these high risk pregnancies is often further complicated by the patient's need for dialysis as a result of lupus nephritis (LN). We share our experience in managing two LN patients with successful pregnancies, one on automated peritoneal dialysis and the other on haemodialysis, as well as a review of cases in the literature.

\section{Introduction}

Pregnancy is an uncommon event in patients with end stage kidney disease (ESKD). According to current Australian statistics from the Australian and New Zealand Dialysis and Transplant (ANZDATA) registry, there have been 105 reported cases of pregnancy in dialysis patients from 1973 to 2009 [1]. Successful pregnancy in a patient with lupus nephritis (LN) and on dialysis is an uncommon occurrence, and this presents a challenge not only to the nephrologist but also to the other medical specialities involved in the care of the patient.

We present two cases of pregnancy with LN on dialysis from our centre. The first is a rare case of a patient with LN initially on automated peritoneal dialysis (APD) during pregnancy. Our case is the first report in Australia of a successful pregnancy in a patient on APD for ESKD due to LN.

The second case is of a patient who had ESKD due to LN who required haemodialysis (HD) during her pregnancy. Both pregnancies resulted in live births which continue to thrive. Cases of pregnancy in patients with $\mathrm{LN}$ on dialysis are still uncommon occurrences, and we have reviewed the cases reported in the literature, along with our own centre's experience, in managing these patients.

\section{Case One}

A 30-year-old female with ESKD on APD who at the time of her pregnancy was a gravida 4 , para 1 , and abortus 2 was admitted to our hospital. She had a 14-year-old son born by spontaneous vaginal delivery a year before she was diagnosed with systemic lupus erythematosus (SLE), and subsequently she has had two medical terminations of pregnancy due to SLE flares. SLE was diagnosed at age 17, and over the years it had manifested with arthralgia, episcleritis, seizures, and a biopsy proven WHO Class IV lupus nephritis and advanced ESKD. She had started APD at 28 years of age.

At 9 weeks of gestation, she was transferred to our tertiary institution from one of the peripheral hospitals in order to plan coordinated care of her pregnancy with nephrologists, obstetric physicians, haematologists, obstetricians, and rheumatologists.

At the initial pregnancy assessment, her blood pressure (BP) was $95 / 60 \mathrm{~mm} \mathrm{Hg}$ with a symptomatic postural drop 
of $25 \mathrm{~mm} \mathrm{Hg}$. Because of this, her prepregnancy regimen of one 6 -litre bag of $1.5 \%$ and two bags of $2.5 \%$ over 8 hours with 6 cycles was changed to three $1.5 \% 6$-litre bags. She had no clinical signs of lupus activity, and laboratory investigations showed a haemoglobin of $96 \mathrm{~g} / \mathrm{L}$, platelet count of 319 , erythrocyte sedimentation rate $122 \mathrm{~mm} / \mathrm{hr}, \mathrm{C} 30.08 \mathrm{~g} / \mathrm{L}$, C4 $0.67 \mathrm{~g} / \mathrm{L}$, anti-double-stranded DNA antibody (dsDNA) $28 \mathrm{IU} / \mathrm{mL}$, positive direct Coombs' test, and low haptoglobin $0.19 \mathrm{~g} / \mathrm{L}$ but normal reticulocyte count, lactose dehydrogenase (LDH), and bilirubin. She was started on plaquenil and prednisolone for microangiopathic haemolytic anaemia (MAHA).

The patient was counselled about the risks both to her and foetus, of continuing with the pregnancy, and she made an informed decision to proceed with the pregnancy. She was started on low dose aspirin and daily enoxaparin for preeclampsia prophylaxis. During pregnancy, the dose of erythropoietin stimulating agent (ESA) was titrated according to haemoglobin.

The PD regimen was modified throughout her pregnancy with the aim of keeping blood urea at or less than $15 \mathrm{mmol} / \mathrm{L}$. At 20 of weeks gestation, urea increased, and she was switched to continuous ambulatory peritoneal dialysis (CAPD) to allow for better variance of her prescription. The total dose of $\mathrm{PD}$ was five exchanges with $1.5 \%$ bags with volumes of 1.5 litres.

At 31 weeks of gestation, the patient developed preeclampsia manifested by blood pressure of 180/110 $\mathrm{mm} \mathrm{Hg}$, headache, and epigastric pain. A $900 \mathrm{~g}$ male baby was delivered by emergency transperitoneal lower segment caesarean section with Apgar scores 7 and 9 at 1 and 5 minutes, respectively. The baby was admitted to a special care nursery where he required supplemental oxygen but was otherwise well.

The patient started on $\mathrm{HD}$ via a central venous dialysis catheter at day 2 postpartum. She was discharged on day 5 postpartum and continued on HD until day 20 when she restarted PD. Throughout her pregnancy and in the postpartum period, no other features of lupus activity manifested apart from the MAHA.

\section{Case Two}

The second case is of a 20-year-old female who was gravida 1 , para 0 , and abortus 0 diagnosed with SLE at the age of 15. She presented initially with arthralgia and subsequently developed biopsy proven WHO class IV LN at the age of 18. She was commenced on steroids and mycophenolate mofetil, but renal dysfunction progressed to ESKD due to nonadherence with therapy. She also developed significant hypertension which was treated with amlodipine, perindopril, and candesartan.

Her pregnancy was diagnosed at 6 weeks of gestation. She made an informed decision to proceed with the pregnancy.

At initial assessment, there were no clinical signs of lupus activity. Her BP was $160 / 99 \mathrm{~mm} \mathrm{Hg}$, and laboratory investigations showed a urea of $17.9 \mathrm{mmol} / \mathrm{L}$, creatinine $253 \mu \mathrm{M} / \mathrm{L}$, estimated glomerular filtration rate (eGFR) 21 , haemoglobin of $89 \mathrm{~g} / \mathrm{L}$ with normal iron studies, vitamin B12 and red cell folate, C3 $0.94 \mathrm{~g} / \mathrm{L}, \mathrm{C} 40.23 \mathrm{~g} / \mathrm{L}$, dsDNA $8 \mathrm{IU} / \mathrm{mL}$, negative direct Coomb's test, normal reticulocyte count, LDH, haptoglobolin, and bilirubin. The antihypertensive medications were changed to methyldopa and labetalol. Low dose aspirin and enoxaparin were given daily for prophylaxis of preeclampsia. She was treated with an ESA to maintain haemoglobin at $110-120 \mathrm{~g} / \mathrm{dL}$.

Throughout the pregnancy, she continued to have elevated blood pressures with systolic blood pressures up to $200 \mathrm{~mm} \mathrm{Hg}$ which resulted in multiple admissions, and her medications included hydralazine and nifedipine.

At 8 weeks of gestation, the patient was started on preemptive HD with an aim to keep urea below $15 \mathrm{mmol} / \mathrm{L}$. The laboratory investigations at the time of dialysis initiation showed a urea of $16.6 \mathrm{mmol} / \mathrm{L}$, creatinine of $274 \mathrm{umol} / \mathrm{L}$, and a decline in eGFR to 19 . Her dialysis prescription initially was for 6 times a week, 3 hours using a F8 dialyser with a blood flow rate (BFR) of $200 \mathrm{~mL} / \mathrm{minute}$ and of dialysate flow rate $300 \mathrm{~mL} / \mathrm{minute}$. Dry weight was assessed at each dialysis, and the aim was for her to have an approximate weight gain of $0.25 \mathrm{~kg} /$ week till 20 weeks of gestation. In order to maintain urea below $15 \mathrm{mmol} / \mathrm{L}$, dialysis duration was increased to 4 hours, and BFR and dialysate flow rate were increased to $250 \mathrm{~mL} / \mathrm{min}$ and $500 \mathrm{~mL} / \mathrm{min}$, respectively, at 22 weeks of gestation.

She was admitted to hospital at 29 weeks of gestation following a two-day history of feeling unwell and intermittent nausea. Cardiotocography on admission showed poor variability. Fetal ultrasounds scan showed intrauterine growth restriction (IUGR) with an estimated fetal weight of 975 grams which was below the third centile. She received steroid prophylaxis. The patient had an emergency lower segment caesarean section with the birth of a $906 \mathrm{~g}$ live male infant with Apgar scores of 1, 2, and 8 at 1, 5, and 10 minutes. The baby was admitted to the special care nursery where he continued to progress well.

\section{Case Discussion}

SLE predominantly affects women of childbearing age and therefore pregnancy in SLE is a significant concern. Fertility in patients with SLE is similar to the general population though pregnancy in patients with ESKD and patients on dialysis is uncommon [2]. The incidence in Australia from 1973 to 2009 is $0.6 \%$ [1]. Contraceptive use is encouraged in these patients to ensure that pregnancy does not occur during a period of lupus activity, preferably delaying conception until 6 months of quiescence [3]. The advice can be largely attributed to the three-fold increased risk of stillbirth for pregnancies with active SLE activity, despite insignificant increase in miscarriages [4]. The estimated pregnancy rate is likely to be higher as the number of abortions is unknown and not always included. The low pregnancy rate is due to reduced fertility caused by changes in hormones regulating reproductive function which results in anovulation. It has also been linked to reduced libido in ESKD patients.

The first report of a successful pregnancy in a chronic HD patient was made by Confortini et al. in the early 1970 s [5]. Pregnancy in patients with ESKD is associated with both fetal and maternal adverse outcomes, and in the past most 
TABLE 1: Cases of live births in dialysis patients with systemic lupus erythematous in the literature.

\begin{tabular}{|c|c|c|c|c|c|}
\hline Dialysis modality & Age & Weeks of gestation & Birth weight (g) & Complications & Reference \\
\hline Peritoneal dialysis & 39 & 36 & 2338 & Preeclampsia & Hou et al. [21] \\
\hline Peritoneal dialysis & 27 & 39 & 2480 & $\begin{array}{c}\text { Haemorrhagic peritoneal } \\
\text { drainage fluid, pre-eclampsia }\end{array}$ & Altay et al. [27] \\
\hline Haemodialysis & 25 & 32 & 1400 & $\begin{array}{c}\text { Hypertension, Diabetes } \\
\text { mellitus }\end{array}$ & Malik et al. [28] \\
\hline Haemodialysis & 26 & 31 & 1810 & Hypertension & \multirow{3}{*}{ Chou et al. [29] } \\
\hline Peritoneal dialysis & 39 & 35 & 2388 & Preterm & \\
\hline Peritoneal dialysis & 31 & 34 & 1004 & Intrauterine growth restriction & \\
\hline Haemodialysis & 20 & 35 & 1440 & $\begin{array}{l}\text { Hypertension, fetal distress, } \\
\text { anaemia, and haemorrhage }\end{array}$ & \multirow{2}{*}{ Romão et al. [30] } \\
\hline Haemodialysis & 22 & 27 & 1030 & $\begin{array}{c}\text { Fetal distress, anaemia, and } \\
\text { haemorrhage }\end{array}$ & \\
\hline
\end{tabular}

clinicians discouraged pregnancy in patients with ESKD. Maternal risks include hypertension whilst fetal risks include IUGR and prematurity. A rise in fertility rates has been noted as dialysis care has improved. An increase in the number of chronic dialysis patients who have menstrual periods has been noted, with Holley et al. finding a rate of $50 \%$ [6]. In the late 1970s Perez et al. had reported the incidence as 10\% [7]. It is known however that not all menstrual cycles are associated with ovulation. Patients with residual renal function are more likely to ovulate, and thus pregnancy is more likely to occur during the early years of dialysis. Both of our patients still had residual renal function and both patients made 700$800 \mathrm{~mL}$ urine/day. Wing et al. report a series of pregnancies occurring after an average length of dialysis of 2.2 years, and Giatras et al. noted that $47 \%$ of pregnancies reported occurred during the first two years on dialysis $[8,9]$. There are case reports of patients falling pregnant after being on dialysis for longer with Hsieh et al. reporting three cases of pregnancy in women who had been on dialysis for more than five years [10]. A correlation between an increased time on dialysis during pregnancy and improved outcomes during pregnancy has been observed [11].

The incidence of pregnancy is two to three times more common in HD patients compared with PD patients [11]. It is unclear whether the difference is due to an effect of PD itself or due to differences in hormonal milieu.

Of the documented 105 pregnancies in a 36-year period for Australian ESKD patients on dialysis, $48 \%$ of the pregnancies resulted in a live delivery. Seven of these pregnancies were in patients with SLE, and of these only one had a live delivery [1]. This illustrates the poor outcomes that are associated with pregnancy in SLE patients. Severe hypertension is the most life-threatening complication of pregnancy in ESKD patients [12]. These complications are more severe in patients with SLE if there is evidence of disease activity at the time of conception or early in the pregnancy [4]. These complications highlight reasons for the rare occurrences of successful pregnancies on dialysis as a result of SLE, and Table 1 summarises the cases present in the literature.

\section{Management of Pregnancy}

For antenatal management, Dudley and Branch have suggested fortnightly visits for the first and second trimester with weekly visits in the third trimester [13].

Once pregnancy has been confirmed, it is important to review the patient's current medications in regard to safety in their use during pregnancy. Tables 2(a) and 2(b) list commonly used drugs in dialysis and SLE, respectively, along with current safety ratings by Australian Therapeutic Goods Administration [14]; Table 2(c) lists the key for these ratings [15].

There is variation on whether pregnancy increases the risk of flares with some authors quoting an increased risk of a flare of LN during pregnancy,while others report no increased risk of flares when compared with nonpregnant patients [16-18]. Flares can occur at any time during the pregnancy or in the postpartum period. The frequency of flares is higher in patients with active lupus at conception and also in those with a positive lupus anticoagulant. In our patient, this manifested as MAHA which was controlled with plaquenil and steroids. Measurement of complement levels is one of the parameters assessed for lupus activity, and this normally manifests with reduced complement levels. In pregnancy, however, the complement levels can increase up to $50 \%$ from increased synthesis, and thus when assessing for disease activity, a downward trend or a low normal level may still indicate disease activity.

Patients on PD are less likely to achieve pregnancy than HD [19]. Possible causes for this difference may be a result of the hypertonic dialysate in the peritoneum or from prior occurrences of peritonitis causing adhesions and failure of implantation [11]. Our case one was already on APD, and this was continued during the pregnancy with change to CAPD in the latter stages of pregnancy. There is very little in the literature in terms of guidelines for PD in pregnancy. The potential advantages of PD are that it allows for continuous dialysis and less changes in the intravascular maternal volumes when compared with HD. 
TABLE 2: (a) Safety in pregnancy: drugs commonly used in dialysis. (b) safety in pregnancy: drugs commonly used in systemic lupus erythematous. (c) Key to categories for prescribing medicines in pregnancy.

(a)

\begin{tabular}{|c|c|}
\hline Drug & $\begin{array}{c}\text { Australian } \\
\text { category for } \\
\text { prescribing } \\
\text { medicines in } \\
\text { pregnancy [14] }\end{array}$ \\
\hline ACE inhibitors & $\mathrm{D}$ \\
\hline Angiotensin II receptor blockers & $\mathrm{D}$ \\
\hline Calcium channel blockers & $\mathrm{C}$ \\
\hline Beta-adrenergic blocking agents & $\mathrm{C}$ \\
\hline \multicolumn{2}{|l|}{ Diuretics } \\
\hline Aldosterone antagonist & B3 \\
\hline Carbonic anhydrase inhibitor & B3 \\
\hline Loop diuretic & $\mathrm{C}$ \\
\hline Potassium-sparing diuretic & $\mathrm{C}$ \\
\hline Thiazide diuretic & $\mathrm{C}$ \\
\hline Thiazide-like diuretic & $\mathrm{C}$ \\
\hline Vasopressin receptor 2 antagonist & $\mathrm{D}$ \\
\hline \multicolumn{2}{|l|}{ Phosphate binders } \\
\hline Lanthanum carbonate & B3 \\
\hline Sevelamer & B3 \\
\hline Erythropoietin & A \\
\hline \multicolumn{2}{|l|}{ Iron } \\
\hline Iron polymaltose & A \\
\hline Iron sucrose & B3 \\
\hline \multicolumn{2}{|l|}{ Bone disease } \\
\hline Calcitriol & B3 \\
\hline Paricalcitol & $\mathrm{C}$ \\
\hline Cinacalcet & B3 \\
\hline \multicolumn{2}{|l|}{ Itching } \\
\hline Diphenhydramine & $\mathrm{A}$ \\
\hline Hydroxyzine & A \\
\hline Cetrizine & $\mathrm{B} 2$ \\
\hline
\end{tabular}

(b)

\begin{tabular}{lc}
\hline Drug & $\begin{array}{c}\text { Australian category } \\
\text { for prescribing } \\
\text { medicines in } \\
\text { pregnancy [14] }\end{array}$ \\
\hline Hydroxychloroquine & $\mathrm{D}$ \\
Azathioprine & $\mathrm{D}$ \\
Mycophenolate mofetil & $\mathrm{D}$ \\
Cyclophosphamide & $\mathrm{D}$ \\
Cyclosporin & $\mathrm{C}$ \\
Corticosteroids & $\mathrm{A}$ \\
$\begin{array}{l}\text { Nonsteroidal anti-inflammatory } \\
\text { drugs (NSAIDs) }\end{array}$ & $\mathrm{C}$ \\
\hline
\end{tabular}

(c)

\begin{tabular}{|c|c|}
\hline \multicolumn{2}{|c|}{ Category Definition [15] } \\
\hline A & $\begin{array}{l}\text { Drugs which have been taken by a large number of } \\
\text { pregnant women and women of childbearing age } \\
\text { without any proven increase in the frequency of } \\
\text { malformations or other direct or indirect harmful } \\
\text { effects on the foetus having been observed. }\end{array}$ \\
\hline B1 & $\begin{array}{l}\text { Drugs which have been taken by only a limited number } \\
\text { of pregnant women and women of childbearing age, } \\
\text { without an increase in the frequency of malformation } \\
\text { or other direct or indirect harmful effects on the human } \\
\text { foetus having been observed. } \\
\text { Studies on animals have not shown evidence of an } \\
\text { increased occurrence of fetal damage. }\end{array}$ \\
\hline B2 & $\begin{array}{l}\text { Drugs which have been taken by only a limited number } \\
\text { of pregnant women and women of childbearing age, } \\
\text { without an increase in the frequency of malformation } \\
\text { or other direct or indirect harmful effects on the human } \\
\text { foetus having been observed. } \\
\text { Studies on animals are inadequate or may be lacking, } \\
\text { but available data show no evidence of an increased } \\
\text { occurrence of fetal damage. }\end{array}$ \\
\hline B3 & $\begin{array}{l}\text { Drugs which have been taken by only a limited number } \\
\text { of pregnant women and women of childbearing age, } \\
\text { without an increase in the frequency of malformation } \\
\text { or other direct or indirect harmful effects on the human } \\
\text { foetus having been observed. } \\
\text { Studies on animals have shown evidence of an } \\
\text { increased occurrence of fetal damage, the significance } \\
\text { of which is considered uncertain in humans. }\end{array}$ \\
\hline $\mathrm{C}$ & $\begin{array}{l}\text { Drugs which, owing to their pharmacological effects, } \\
\text { have caused or may be suspected of causing, harmful } \\
\text { effects on the human foetus or neonate without causing } \\
\text { malformations. These effects may be reversible. } \\
\text { Accompanying texts should be consulted for further } \\
\text { details. }\end{array}$ \\
\hline $\mathrm{D}$ & $\begin{array}{l}\text { Drugs which have caused, are suspected to have caused, } \\
\text { or may be expected to cause an increased incidence of } \\
\text { human fetal malformations or irreversible damage. } \\
\text { These drugs may also have adverse pharmacological } \\
\text { effects. Accompanying texts should be consulted for } \\
\text { further details. }\end{array}$ \\
\hline $\mathrm{X}$ & $\begin{array}{l}\text { Drugs which have such a high risk of causing } \\
\text { permanent damage to the foetus that they should not be } \\
\text { used in pregnancy or when there is a possibility of } \\
\text { pregnancy. }\end{array}$ \\
\hline
\end{tabular}

The aim of increasing dialysis in pregnancy is to provide a less azotemic uterine environment. Holley et al. suggest starting dialysis at a $28.6 \mathrm{mmol} / \mathrm{L}$ urea and aiming to keep it below $18 \mathrm{mmol} / \mathrm{L}$, while Jefferys and colleagues recommend keeping the urea less than $10 \mathrm{mmol} / \mathrm{L}$ and the creatinine as low as possible $[6,20]$. With both our patients, we aimed to keep the urea less than $15 \mathrm{mmol} / \mathrm{L}$. The increased dialysis delivery also allows for lifting of dietary restrictions and results in less hypotensive episodes in HD patients. Dialysis times in HD patients are generally increased to greater than 20 hours per week. 
Table 3: Pregnancy and dialysis monitoring guidelines at the Renal Department of the Royal Brisbane and Women's Hospital.

\begin{tabular}{|c|c|}
\hline Guideline & Recommendation/observations/frequency \\
\hline \multicolumn{2}{|l|}{ Dialysis prescription } \\
\hline \multicolumn{2}{|l|}{$H D$} \\
\hline Dialyser & High-flux, high-efficiency \\
\hline Duration and frequency & At least $20 \mathrm{~h} /$ week \\
\hline Blood flow rate & $300 \mathrm{~mL} / \mathrm{min}$ \\
\hline Dialysate flow rate & $500 \mathrm{~mL} / \mathrm{min}$ \\
\hline Dialysate composition & Calcium $1.75 \mathrm{mmol} / \mathrm{L}$, bicarbonate $25 \mathrm{mmol} / \mathrm{L}$, and glucose $5 \mathrm{mmol} / \mathrm{L}$ \\
\hline Weight review & Weekly clinically + blood volume monitoring weekly \\
\hline Fluid status & Prefered to leave "wet" as opposed to dry to avoid hypotension \\
\hline Anticoagulation & Unfractionated heparin ( $1500 \mathrm{u}$ bolus and $750 \mathrm{u}$ hourly; off for the last 60 minutes) \\
\hline Erythropoietin therapy & Recommendation to maintain haemoglobin $>110 \mathrm{~g} / \mathrm{L}$. May need higher doses \\
\hline Iron therapy & Intravenous iron to maintain transferrin saturation $>25 \%$ \\
\hline Vital signs & Each dialysis \\
\hline Blood pressure parameters & Avoidance of hypotension imperative \\
\hline \multicolumn{2}{|l|}{$\begin{array}{l}\text { ensure that phosphate binders and active vitamin } \\
\mathrm{D} \text { are adjusted as needed }\end{array}$} \\
\hline Pathology $y^{*}$ & $\begin{array}{l}\text { Perform full blood counts, electrolyte, and liver function tests weekly. Vitamin B12 } \\
\text { checked every } 3 \text { months. Check dialysis adequacy using Kt/V ratio weekly. Other } \\
\text { bloods as routinely done in dialysis patients }\end{array}$ \\
\hline Haemoglobin & Maintain $110-120 \mathrm{~g} / \mathrm{L}$ \\
\hline Iron studies & Aim to achieve a transferrin saturation above $25 \%$ \\
\hline Vitamin B12/folate & Suggest supplement folate $5 \mathrm{mg}$ daily \\
\hline Magnesium & Keep in normal range \\
\hline Urea & Aim to keep pre-dialysis $<15 \mathrm{mmol} / \mathrm{L}$ \\
\hline Bicarbonate & Keep in normal range before dialysis \\
\hline Phosphate & When dialysis hours increased it is important to avoid low phosphate \\
\hline Urate & Monitor levels \\
\hline \multicolumn{2}{|l|}{ Diet $^{*}$} \\
\hline High protein & Dietician to review regularly \\
\hline Supplements & $\begin{array}{l}\text { Suggest folate } 5 \mathrm{mg} \text { daily, vitamin B1 daily, vitamin D } 1000 \text { iu daily, and calcitriol } \\
\text { (adjust according to phosphate and calcium) }\end{array}$ \\
\hline Aspirin & To consider this in consultation with obstetric physicians/obstetricians \\
\hline \multicolumn{2}{|l|}{ Fetal monitoring ${ }^{*}$} \\
\hline Ultrasonography & Frequent to monitor growth discussision with obstetricians/obstetric physicians \\
\hline
\end{tabular}

${ }^{*}$ Guidelines also apply for peritoneal dialysis.

Increasing dialysis may also be beneficial in reducing polyhydramnios risk as this is thought to be caused by urea diuresis in the foetus. In a case series of 5 patients with ESRD managed with CAPD during their pregnancies, none of them developed polyhydramnios and the authors suggest that this was due dialysis being initiated preemptively [20].

The dialysate bicarbonate composition may need alteration due to the more frequent dialysis and the normal metabolic changes that occur in pregnancy. Respiratory alkalosis occurs in normal pregnancy and is compensated for by metabolic acidosis, resulting in a serum bicarbonate level of $18-20 \mathrm{mmmol} / \mathrm{L}$. Hou et al. thus recommend the reduction of dialysate bicarbonate in order to prevent the flux of bicarbonate from dialysate given the increased frequency of dialysis [21].

Anaemia is common in normal pregnancy, and pregnancy is known to cause resistance to erythropoietin. This is thought to be mediated by cytokines whose production is increased in pregnancy. In the case of our first patient, haemolytic anaemia also contributed as did HD in the second case. Both patients were managed with an ESA titration to target haemoglobin of $110-120 \mathrm{~g} / \mathrm{L}$.

Hypertension management is critical, and in pregnant dialysis patients, in addition to monitoring for preeclampsia, assessment of fluid status is vital as the raised blood pressure may be due to fluid accumulation. It is particularly important 
in pregnant patients to carefully remove fluid as hypotension may result in uterine hypoperfusion. Both our patients also had an increased risk of preeclampsia due to SLE (30-50\%) as compared with an incidence of $6-10 \%$ in the general population $[13,22]$. The use of low dose aspirin and heparin is a well-known method of reducing risk of preeclampsia [23, 24]. The presence of the antiphospholipid antibody further increases risk of hypertension as this antibody predisposes to arterial hypertension by causing endothelial damage.

Making the distinction between a flare of LN and preeclampsia can be difficult as both conditions can present with hypertension, peripheral oedema, and proteinuria. Severe cases of HELLP syndrome can also manifest with MAHA. Differentiating the two conditions requires both clinical and laboratory measurements. Lupus flares are more likely to be present if accompanied by hypocomplementemia, high or rising anti-dsDNA antibody titre, and active urinary sediment. It is important to make the distinction as the treatment modalities are entirely different.

Caesarean section can be transperitoneal or extraperitoneal. Our patient had a transperitoneal caesarean section and restarted peritoneal dialysis at day 20 . Hou recommends that peritoneal dialysis can be restarted at 24 hours if caesarean section is done extraperitoneally [25].

Managing the multiple aspects of LN pregnancy with dialysis can be a challenge, and no set guidelines exist for these rare cases. Table 3 shows the general management guidelines at our centre for such cases.

\section{Fetal Outcomes}

In a review of pregnancies of women on chronic HD from 1992-2003, Holley and Reddy analysed 6 separate reports of pregnancies, and the average percentage of surviving infants was $43 \%$ [11]. This is double the percentage previously described in 1980 by the Registration Committee of the European Dialysis and Transplant Association [26].

Hypertension is frequently seen in lupus pregnancy which leads to both prematurity and IUGR [18].

\section{Conclusion}

Pregnancy in patients with ESRD and in particular in patients with LN is associated with a high fetal and maternal risk. With close maternal and fetal surveillance in conjunction with multidisciplinary management, favourable outcomes are possible in such patients. We report two cases managed by two different modes of dialysis, both resulting in successful outcomes.

\section{Conflict of Interests}

The authors declare that there is no conflict of interests regarding the publication of this paper.

\section{References}

[1] Australia and New Zealand Dialysis and Transplant Registry (ANZDATA), 2009.
[2] M. A. Khamashta and G. R. V. Hughes, "Pregnancy in systemic lupus erythematosus," Current Opinion in Rheumatology, vol. 8, no. 5, pp. 424-429, 1996.

[3] M. Petri, “The Hopkins Lupus Pregnancy Center: ten key issues in management," Rheumatic Disease Clinics of North America, vol. 33, no. 2, pp. 227-235, 2007.

[4] M. E. B. Clowse, "Lupus Activity in Pregnancy," Rheumatic Disease Clinics of North America, vol. 33, no. 2, pp. 237-252, 2007.

[5] P. Confortini, G. Galanti, G. Ancona et al., "Full-term pregnancy and successful delivery in a patient on chronic haemodialysis," Proceedings of the European Dialysis and Transplant Association, vol. 8, pp. 74-80, 1971.

[6] J. L. Holley, R. J. Schmidt, F. H. Bender, F. Dumler, and M. Schiff, "Gynecologic and reproductive issues in women on dialysis," American Journal of Kidney Diseases, vol. 29, no. 5, pp. 685-690, 1997.

[7] R. J. Perez, H. Lipner, and N. Abdulla, "Menstrual dysfunction of patients undergoing chronic hemodialysis," Obstetrics and Gynecology, vol. 51, no. 5, pp. 552-555, 1978.

[8] A. J. Wing, F. P. Brunner, H. Brynger et al., "Successful pregnancies in women treated by dialysis and kidney transplantation," British Journal of Obstetrics and Gynaecology, vol. 87, pp. 839845, 1980.

[9] I. Giatras, D. P. Levy, F. D. Malone, J. A. Carlson, and P. Jungers, "Pregnancy during dialysis: case report and management guidelines," Nephrology Dialysis Transplantation, vol. 13, no. 12, pp. 3266-3272, 1998.

[10] T. T. Hsieh, K. C. Chen, B. J. Cheng, and T. H. Chiu, "Pregnancy outcome in patients undergoing long-term hemodialysis," Acta Obstetricia et Gynecologica Scandinavica, vol. 70, no. 4-5, pp. 299-302, 1991.

[11] J. L. Holley and S. S. Reddy, "Pregnancy in dialysis patients: a review of outcomes, complications, and management," Seminars in Dialysis, vol. 16, no. 5, pp. 384-388, 2003.

[12] S. Hou and S. D. Grossman, "Pregnancy in chronic dialysis patients," Seminars in Dialysis, vol. 3, no. 4, pp. 224-229, 1990.

[13] D. J. Dudley and D. W. Branch, "Prenancy in the patient with rheumatic disease: the obstetrician's perspective," Balliere's Clinical Rheumatology, vol. 4, pp. 150-151, 1990.

[14] Therapeutic Goods Administration, Australia, "Prescribing medicines in pregnancy database," 2013, http://www.tga.gov.au/ $\mathrm{hp} /$ medicines-pregnancy.htm.

[15] Therapeutic Goods Administration, Australia, "Australian categorisation system for prescribing medicines in pregnancy," 2013, http://www.tga.gov.au/hp/medicines-pregnancy-categorisation.htm.

[16] A. Tincani, D. Faden, M. Tarantini et al., "Systemic lupus erythematosus and pregnancy: A Prospective Study," Clinical and Experimental Rheumatology, vol. 10, no. 5, pp. 439-446, 1992.

[17] M. Petri, D. Howard, and J. Repke, "Frequency of lupus flare in pregnancy: The Hopkins Lupus Pregnancy Center experience," Arthritis and Rheumatism, vol. 34, no. 12, pp. 1538-1545, 1991.

[18] M. B. Urowitz, D. D. Gladman, V. T. Farewell, J. Stewart, and J. McDonald, "Lupus and pregnancy studies," Arthritis and Rheumatism, vol. 36, no. 10, pp. 1392-1397, 1993.

[19] A. K. Shahir, N. Briggs, J. Katsoulis et al., "An observational outcomes study from 1966-2008, examining pregnancy and neonatal outcomes from dialysed women using data from the ANZDATA Registry," Nephrology, vol. 18, pp. 276-284, 2013. 
[20] A. Jefferys, K. Wyburn, J. Chow, B. Cleland, and A. Hennessy, "Peritoneal dialysis in pregnancy: A case series," Nephrology, vol. 13, no. 5, pp. 380-383, 2008.

[21] C.-H. Hou, C.-N. Lee, K.-Y. Hung, C.-H. Huang, T.-J. Tsai, and C.-Y. Chen, "An unexpected pregnancy causes poor drainage in automated peritoneal dialysis," Nephrology Dialysis Transplantation, vol. 11, no. 11, pp. 2335-2337, 1996.

[22] M. D. Lockshin, T. Qamar, and M. L. Druzin, "Hazards of lupus pregnancy," Journal of Rheumatology, vol. 14, pp. 214-217, 1987.

[23] M. Knight, L. Dudley, and D. I. Handerson, Antiplatelet Agents for Preventing Pre-Eclampsia (Cochrane Review), The Renal Health Library, 2005.

[24] P. Kincaid-Smith, R. A. North, K. F. Firly et al., "Prevention of pre-eclampsia in high risk women with renal disease in a prospective randomized trial of heparin dipyridamole," Nephrology, vol. 1, pp. 297-300, 1995.

[25] S. Hou, "Conception and pregnancy in peritoneal dialysis patients," Peritoneal Dialysis International, vol. 21, no. 3, pp. S290S294, 2001.

[26] Registration Committee of the European Dialysis and Transplant Association, "Successful pregnancies in women treated by dialysis and Kidney transplantation," British Journal of Obstetrics \& Gynaecology, vol. 87, pp. 839-845, 1980.

[27] M. Altay, H. Akay, H. Parpucu, M. Duranay, and Y. Oguz, "A rare case: full-term delivery in a Lupus patient on CAPD," Peritoneal Dialysis International, vol. 27, no. 6, pp. 711-712, 2007.

[28] G. H. Malik, A. Al-Harbi, S. Al-Mohaya et al., "Pregnancy in patients on dialysis-experience at a referral center," Journal of Association of Physicians of India, vol. 53, pp. 937-941, 2005.

[29] C.-Y. Chou, I.-W. Ting, T.-H. Lin, and C.-N. Lee, "Pregnancy in patients on chronic dialysis: A single center experience and combined analysis of reported results," European Journal of Obstetrics Gynecology and Reproductive Biology, vol. 136, no. 2, pp. 165-170, 2008.

[30] J. E. Romão Jr., C. Luders, S. Kahhale et al., "Pregnancy in women on chronic dialysis. A single-center experience with 17 cases," Nephron, vol. 78, no. 4, pp. 416-422, 1998. 


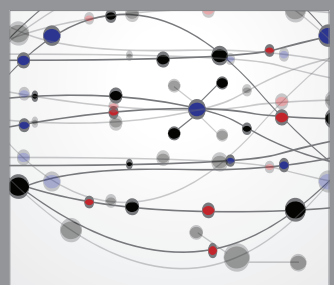

The Scientific World Journal
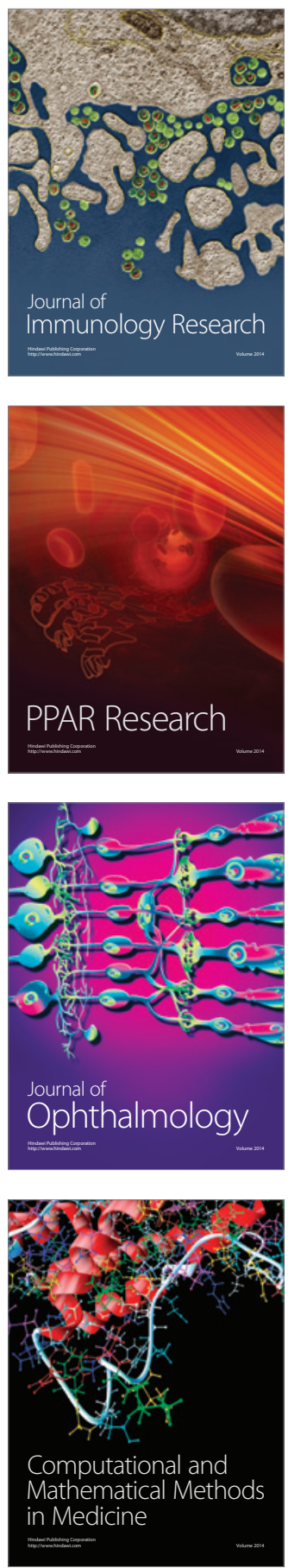

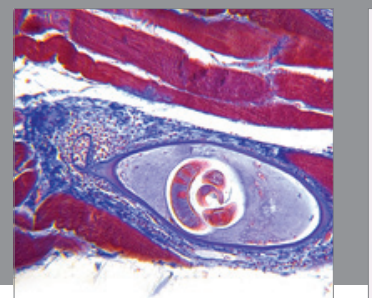

Gastroenterology

Research and Practice
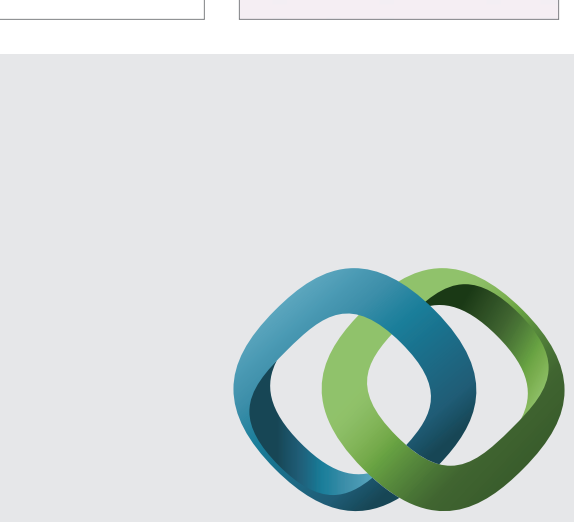

\section{Hindawi}

Submit your manuscripts at

http://www.hindawi.com
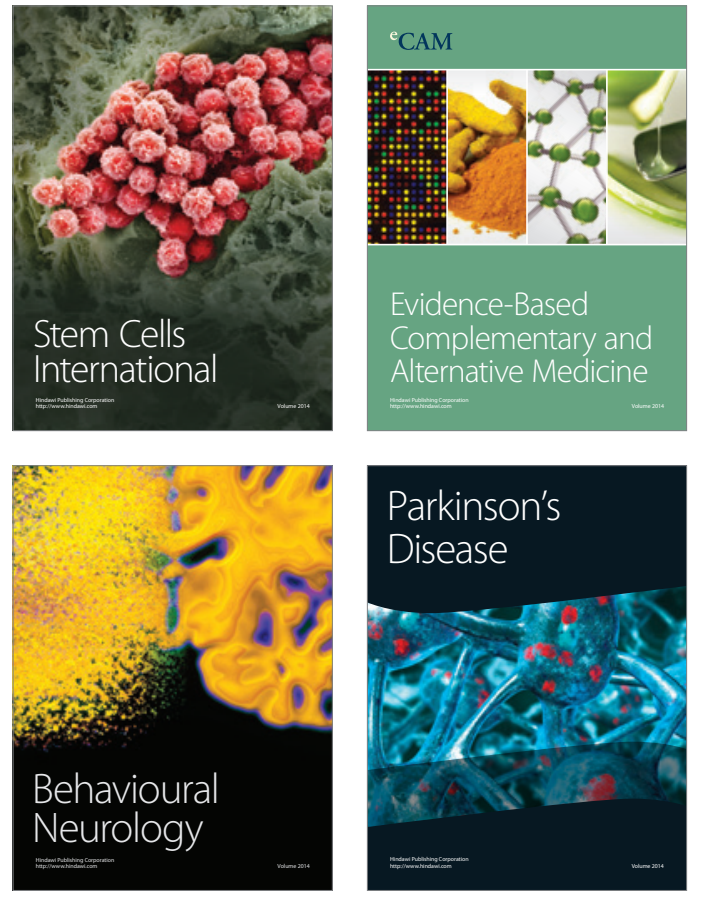
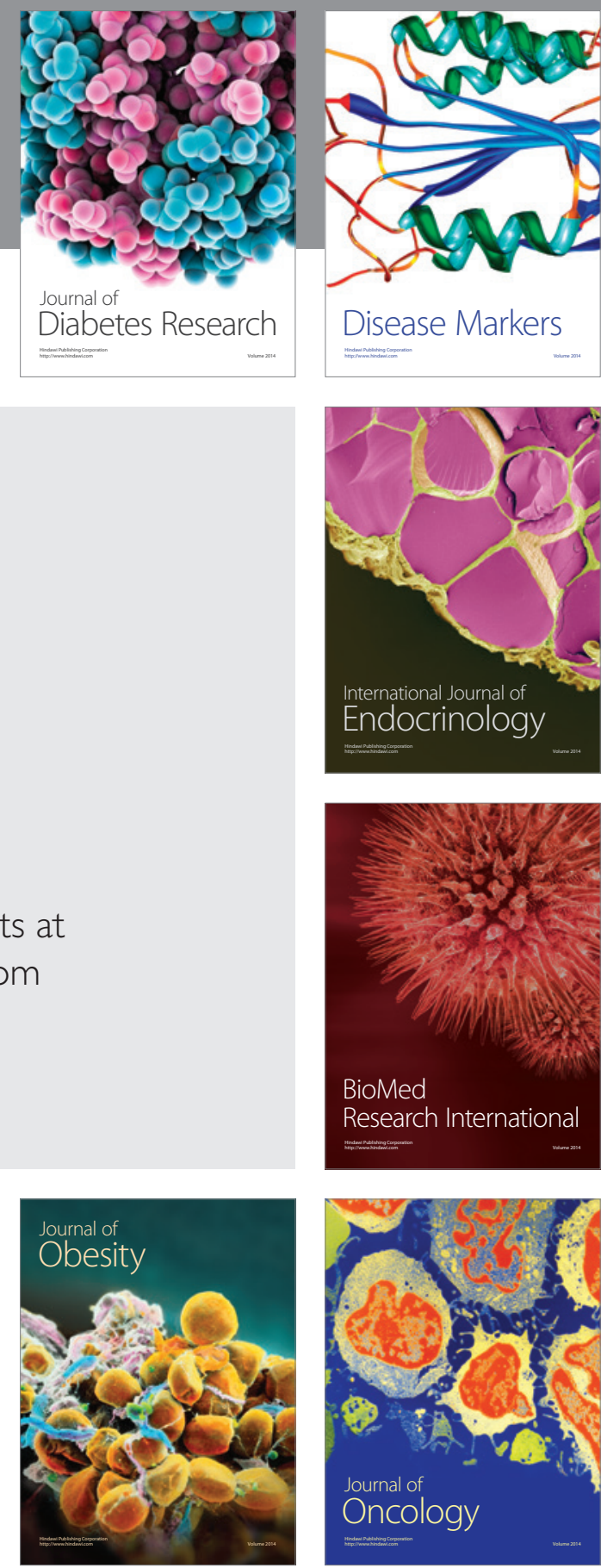

Disease Markers
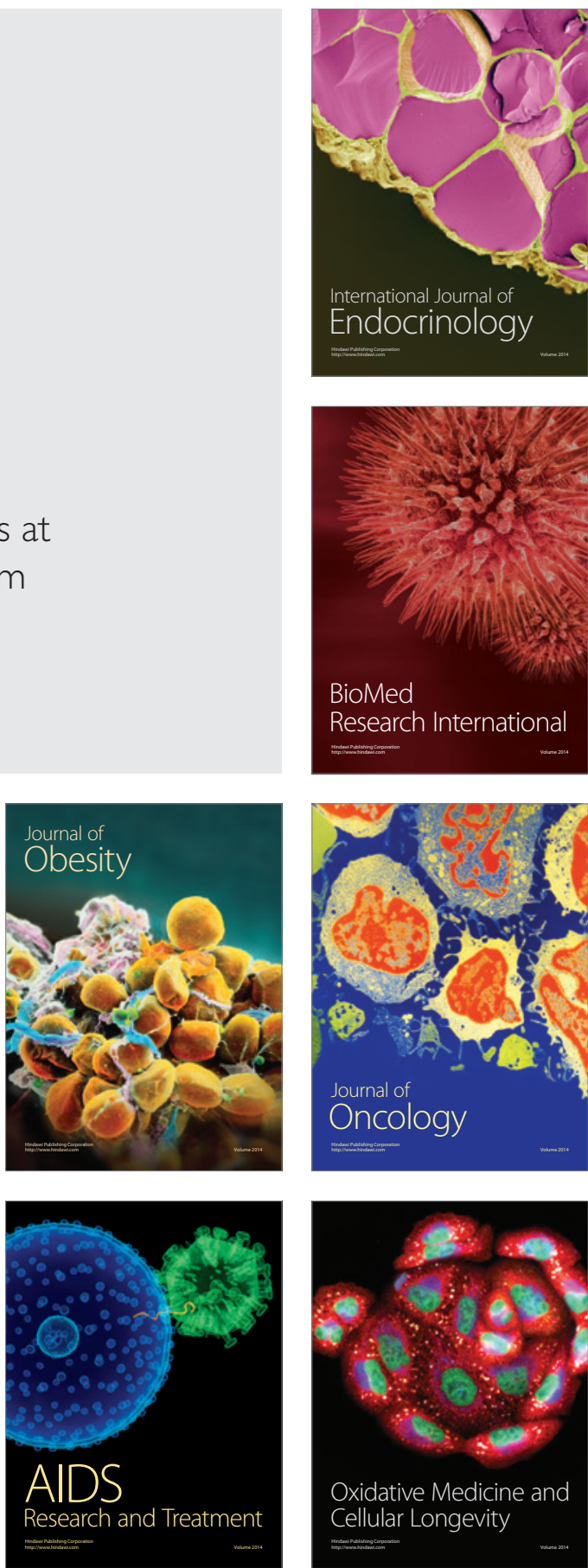